\title{
Sacrificial Template Synthesis of High Surface Area Metal Oxides. Example: An Excellent Structured Fenton-like Catalyst
}

\author{
Tan T. Vu and Gregorio Marbán* \\ Instituto Nacional del Carbón (INCAR-CSIC) - c/Francisco Pintado Fe 26, \\ 33011-Oviedo (Spain). Tel. +34 985119090; Fax +34985297662
}

Article published in Applied Catalysis B: Environmental 152-153, 51-58 2014

\begin{abstract}
Standard sacrificial template synthesis allows metal oxide nanotubes to be produced from $\mathrm{ZnO}$ nanowires. In spite of their high interest in several technological fields, the low surface area of these nanotubes is a drawback for most applications. Here we report for the first time the sacrificial template synthesis of stainless steel wire-mesh (SSWM) supported metal oxides of high technological interest $\left(\mathrm{CuO}, \mathrm{CeO}_{2}, \alpha-\mathrm{Fe}_{2} \mathrm{O}_{3}\right.$ and $\left.\mathrm{TiO}_{2}\right)$ with specific surface area values $\left(84-275 \mathrm{~m}^{2} \mathrm{~g}^{-1}\right)$ that are at least one order of magnitude higher than that of metal oxide nanotubes. The key to achieving this outstanding result was the use of a novel template (SSWM-supported $\mathrm{ZnO}$ nanosheets) with a large proportion of polar surfaces. As an example of application of these materials, a structured reactor with a highly active SSWM-supported $\alpha-\mathrm{Fe}_{2} \mathrm{O}_{3}$ catalyst was successfully tested for the continuous Fenton-like degradation of aqueous Methylene Blue.
\end{abstract}

Keywords: Zinc Oxide, Metal Oxides, Sacrificial Template, Fenton-like Catalyst

\footnotetext{
•Corresponding author: greca@incar.csic.es
} 


\section{Introduction}

Metal oxides of high surface area are used in many applications such as heterogeneous catalysis, wastewater conditioning, the electrochemical storage of energy, sensing, etc [1-5]. There is a great need to develop versatile low temperature synthesis methods for the preparation of nanosized metal oxides with an elevated specific surface area and a high yield on the external surface of flexible metallic supports that will allow microdevices with excellent heat transfer and electrical conductivity properties to be built. Among these supports stainless steel wire meshes (SSWM) of micrometric dimensions have been recently used with great success for supporting high surface area cobalt and zinc oxides [6,7]. In this work, a low temperature method for obtaining nanosized metal oxides supported on SSWM is presented. To demonstrate the potential of this invention, one of the obtained materials (SSWM-supported $\alpha-\mathrm{Fe}_{2} \mathrm{O}_{3}$ ) was successfully employed as a structured catalyst for the continuous degradation of aqueous methylene blue via the heterogeneous Fenton-like reaction with hydrogen peroxide $[8,9]$.

\section{Experimental}

\subsection{Preparation method}

The support was SSWM [with a wire diameter of $30 \mu \mathrm{m}$ and a screen opening of 40 $\mu \mathrm{m}]$ provided by CISA. The SSWM-supported $\mathrm{ZnO}$ was synthesized as described in [7]. In summary, Zinc acetate dihydrate was dissolved together with urea in deionized water. Concentrations of $\mathrm{Zn}^{2+}$ and urea in the aqueous solutions were adjusted to 0.05 and 1.0 $\mathrm{M}$, respectively. The $\mathrm{pH}$ of the solution was adjusted to 4.88 by using acetic acid. The wire mesh was placed in a Teflon autoclave $(100 \mathrm{ml})$ filled with the growth solution. The autoclave was sealed and hydrothermal $\mathrm{ZnO}$ growth proceeded at $80^{\circ} \mathrm{C}$ for $23 \mathrm{~h}$ in 
a constant-temperature water bath. The $\mathrm{ZnO}$ coated-wire mesh was then taken out of the solution, thoroughly washed with deionised water and vacuum-dried at $60^{\circ} \mathrm{C}$. Finally the sample was calcined at $200^{\circ} \mathrm{C}$ for $0.5 \mathrm{~h}$ in air.

To fabricate the copper, cerium and titanium oxides by means of the basic synthesis method, the as-synthesized SSWM-supported $\mathrm{ZnO}$ templates were immersed in plastic flasks containing $50 \mathrm{~mL}$ water solutions of metallic salts. For the preparation of $\mathrm{TiO}_{2}$ boric acid was added to the solution at a $\mathrm{H}_{3} \mathrm{BO}_{3} / \mathrm{K}_{2} \mathrm{TiF}_{6}$ molar ratio of $3 / 1$. The closed flasks were subjected to shaking at RT in an orbital shaker for different durations of time in order to obtain different degrees of metal substitution. To synthesize the iron oxides by the dropwise synthesis method, water solutions (50 mL) of iron (III) nitrate or iron (II) sulphate were slowly pumped with a syringe pump into plastic flasks containing $50 \mathrm{~mL}$ of water and the SSWM-supported $\mathrm{ZnO}$ templates, while the flasks were shaken in an orbital shaker at RT. Afterwards, the samples were taken out of the flasks and washed with deionized water, vacuum-dried at $60^{\circ} \mathrm{C}$ for $30 \mathrm{~min}$ and calcined in air at $250^{\circ} \mathrm{C}$ (in the case of copper, cerium, iron $\left(\mathrm{ex}-\mathrm{Fe}^{2+}\right)$ and titanium oxides) or at $275^{\circ} \mathrm{C}$ (in the case of iron $\left(\mathrm{ex}-\mathrm{Fe}^{3+}\right)$ oxide) for 2 hours. The calcination temperatures were selected after TGA analyses of the different samples.

\subsection{Material characterization}

The chemical composition of the metal oxides was evaluated by means of atomic absorption spectroscopy. The morphology of the samples was studied by scanning electron microscopy (SEM, FEI Quanta FEG 650 model) and transmission electron microscopy (TEM, JEM -2100F). The X-ray diffraction (XRD) patterns of the catalysts were recorded on a Bruker D8 Advance instrument operating at $40 \mathrm{kV}$ and $40 \mathrm{~mA}$ using $\mathrm{Cu} \mathrm{K} \alpha$ radiation $(\lambda=0.15406 \mathrm{~nm})$. The BET specific surface area of the samples was 
evaluated by means of $\mathrm{N}_{2}$ adsorption isotherms $\left(-196^{\circ} \mathrm{C}\right)$ obtained on a Micromeritics ASAP 2020 analyser. Raman spectra from 100 to $1400 \mathrm{~cm}^{-1}$ were obtained at room temperature using a T64000 System (Horiba).

\subsection{Heterogeneous Fenton-like reaction}

Fenton-like degradation of methylene blue (MB) in aqueous solutions was performed with SSWM-supported $\alpha-\mathrm{Fe}_{2} \mathrm{O}_{3}$ catalysts in two modes; batch and continuous operation. All reactions were carried out in the dark to avoid the influence of light. No acid or base was added to adjust the $\mathrm{pH}$ value of the reaction solution. A batch reaction experiment was carried out in order to compare the catalytic activity of the $\alpha-\mathrm{Fe}_{2} \mathrm{O}_{3}$ powder obtained in this work (scratched from the wire mesh-supported material) with that of yolk-shell structured $\mathrm{Fe}_{2} \mathrm{O}_{3} @$ mesoporous $\mathrm{SiO}_{2}$ particles reported by Cui et al . [10]. The reaction was performed in a magnetically stirred reactor at room temperature, at the same reaction conditions used by Cui et al. [10] $\left(0.5 \mathrm{~g} \cdot \mathrm{L}^{-1} \alpha-\mathrm{Fe}_{2} \mathrm{O}_{3}, 50 \mathrm{mg} \cdot \mathrm{L}^{-1}\right.$ MB, $18 \mathrm{~g} \cdot \mathrm{L}^{-1} \mathrm{H}_{2} \mathrm{O}_{2}$ ). Liquid samples were taken for measurement at given reaction times and centrifuged to remove the $\alpha-\mathrm{Fe}_{2} \mathrm{O}_{3}$ particles. The visible absorption peaks of the analyzed samples were recorded in the $400-800 \mathrm{~nm}$ range by means of a UV-Vis spectrometer (Shimadzu UV-2401PC). The concentration of MB was evaluated from calibration curves using the absorbance at $664 \mathrm{~nm}$.

For the continuous operation mode, a SSWM-supported $\alpha-\mathrm{Fe}_{2} \mathrm{O}_{3}$ catalyst with dimensions of $2.5 \mathrm{~cm} \times 5 \mathrm{~cm}\left(36 \mathrm{mg} \alpha-\mathrm{Fe}_{2} \mathrm{O}_{3}\right)$ was rolled around a stainless steel wire and inserted into a silicone tube with an internal diameter of $4 \mathrm{~mm}$ (Figure 8). A $50 \mathrm{~mL}$ solution containing $50 \mathrm{mg} \cdot \mathrm{L}^{-1} \mathrm{MB}$ and $18 \mathrm{~g} \cdot \mathrm{L}^{-1} \mathrm{H}_{2} \mathrm{O}_{2}$ was introduced into a syringe coated with a black tape (not shown in Figure 2). The $\mathrm{MB} / \mathrm{H}_{2} \mathrm{O}_{2}$ solution was then slowly injected by means of a syringe pump into the silicone tube containing the 
SSWM-supported $\alpha-\mathrm{Fe}_{2} \mathrm{O}_{3}$ (Figure 2). Experiments at different residence times (pumping rates) were performed. For a given experiment the concentration of the exit solution was analyzed every $5 \mathrm{~mL}$ and found to be quite stable during the entire experiment. The final degree of MB degradation was expressed as the average value of all measurements $\left(\left\langle\mathrm{C} / \mathrm{C}_{0}\right\rangle\right)$.

\section{Results and Discussion}

\subsection{Sacrificial template synthesis of high surface area metal oxides}

Of the many synthesis methods described in the scientific and patent literature, mainly for making unsupported metal oxides, hard templating methods are known to be among the most effective in producing high surface area metal oxides in powder form $[11,12]$. However, these methods involve several synthesis steps, including the removal of the template by oxidation or dissolution. Sacrificial template-accelerated hydrolysis (STAH) is a novel hard exotemplating technique [13] that consists in the formation of metal oxide nanotubes via the hydrolysis of metal ions in the vicinity of $\mathrm{ZnO}$ nanowires, generally supported on ITO. Hydrolysis is favoured by the removal of protons due to the simultaneous dissolution of the $\mathrm{ZnO}$ scaffold, which is the distinctive characteristic of this technique. Thus, its main advantage over other classical hard templating approaches is that there is no need for a template removal step. Initially used for the synthesis of $\mathrm{Fe}_{2} \mathrm{O}_{3}$ nanostructures with a high lithium-ion storage capacity [13-15] STAH has also been applied in the preparation of platinum and palladium nanotubes for electrocatalysis and chemical sensing [16, 17], NiO-based electrodes [18, 19], $\mathrm{CeO}_{2}$ nanotubes [20], and active electrocatalysts consisting of mixtures of noble metal nanotubes [21]. The common feature of all these publications is that the $\mathrm{ZnO}$ template is made up of nanowires or nanorods and the metal oxides obtained are in the form of 
nanotubes, with the exception of the $\mathrm{ZnO}-\alpha-\mathrm{Fe}_{2} \mathrm{O}_{3}$ nanosheets described by Qin et al. [14], which have a higher specific surface area $\left(27 \mathrm{~m}^{2} \mathrm{~g}^{-1}\right)$ than nanotube-based materials. The values of the specific surface area and yields of these nanotubes have not been reported in any of the revised papers though their geometrical characteristics (e.g. nanotube diameters of hundreds of nanometers) suggest that their associated specific surfaces areas and yields are low.

As an example of a nanotube-precursor template, Figure 1a shows a SEM image of a SSWM-supported $\mathrm{ZnO}$ sample. The synthesis of this sample has been described in a previous work [22] (denoted there as S0-Bai). It consists of typical hexagonal prisms of large size, very low specific surface area and with a small proportion of polar planes (top of the prisms). Figure $1 \mathrm{~b}$ shows the prisms after they have been immersed in an aqueous solution of iron (III) nitrate. As can be seen, the iron oxide only forms on the external (non-polar) surface of the prisms (as detected by EDX) whereas their inner cores are hollowed out by the etching action of the protons released via the hydrolysis of $\mathrm{Fe}^{3+}$ on the top (polar) surface of the prisms. A scheme of this mechanism is shown in Figure 1. This is a similar mechanism to that proposed by Feng et al. [20].

We discovered that the main difference between the $\mathrm{ZnO}$ template used to produce moderate surface area $\mathrm{ZnO}-\alpha-\mathrm{Fe}_{2} \mathrm{O}_{3}$ nanosheets [14] and that displayed in Figure 1a or those used in the works describing the production of nanotubes is to be found in their polarity. The XRD pattern of the $\mathrm{ZnO}$ in the $\mathrm{ZnO}-\alpha-\mathrm{Fe}_{2} \mathrm{O}_{3}$ nanosheets has a (100)/(002) intensity ratio higher than 1 (Figure 3 in [14]), which indicates that the $\mathrm{ZnO}$ crystals have a greater proportion of polar surfaces [23] than the typical $\mathrm{ZnO}$ nanowires employed in other works (e.g. [13]). The latter present a low (100)/(002) intensity ratio $\left(\mathrm{I}_{100} / \mathrm{I}_{002}<<1\right)$, which evidences the exposure of a large proportion of non-polar surfaces $[22,23]$. It follows from this that metal oxide nanotubes are only produced from 
non-polar $\mathrm{ZnO}$ nanowires. It should also be noted that when $\mathrm{Fe}^{3+}$ is used as precursor (a strongly acidic cation) the STAH reaction occurs readily at ambient conditions over the non-polar $\mathrm{ZnO}$ nanowires [13-15], whereas when much less acidic cations are used, such as $\mathrm{Ni}^{2+}[18]$ or $\mathrm{Ce}^{3+}$ [20] more drastic conditions are needed to produce the nanotubes. Only when the more polar $\mathrm{ZnO}$ is used is it possible to obtain $\mathrm{ZnO}-\alpha-\mathrm{Fe}_{2} \mathrm{O}_{3}$ nanosheets at ambient conditions with mildly acidic cations $\left(\mathrm{Fe}^{2+}\right)$ [14], although up to now there has been no report in the literature on the synthesis of pure metal oxides with polar $\mathrm{ZnO}$. This suggests that, contrary to what Feng et al. affirm [20], the nucleation of metal oxides is not prevented on the polar faces by an electrostatic effect, but by the increased rate of dissolution of the polar faces due to the high acidity of the metallic cations $\left(\mathrm{Fe}^{3+}\right)$. On the other hand, when the metallic cations are less acidic, as in [14], the polar surfaces can be partially substituted by metal oxides.

From this deduction, the following questions naturally arise. Would a highly polar $\mathrm{ZnO}$ template be completely dissolved by the action of a strongly acidic cation? Would the formation of pure and very high surface area metal oxides be possible at ambient conditions with less acidic cations on a polar $\mathrm{ZnO}$ template?

In the present work we have tried to answer these questions by using a high surface area SSWM-supported $\mathrm{ZnO}$ template, the preparation of which has been reported in detail elsewhere [7] (Figure 2). This material displays a high specific surface area $\left(80 \mathrm{~m}^{2} \mathrm{~g}^{-1}\right)$ on a $\mathrm{ZnO}$ mass basis and a high yield (20.5 wt.\%). Furthermore the $\mathrm{ZnO}$ nanosheets show a good adhesion to the support and have a large proportion of polar surfaces (see XRD pattern in Figure 2).

Using the template shown in Figure 2 we attempted to synthesize metal oxides of practical technological interest from aqueous solutions of their metal ions, and established a clear relation between the value of the pKa (minus decimal logarithm of 
the hydrolysis constant) and the result obtained by applying the STAH method at ambient conditions (Table 1).

When the basic synthesis method (see Experimetal section) was used with $\mathrm{Fe}^{3+}$ (a strongly acidic cation), the large amount of $\mathrm{H}^{+}$produced dissolved the $\mathrm{ZnO}$ nanosheets completely before any precipitation of iron oxide started to occur on their surface. In principle, this result answers the first question that we addressed in the preceding discussion: a highly polar $\mathrm{ZnO}$ template is completely dissolved by the action of a strongly acidic cation. However, if the iron (III) nitrate solution is supplied dropwise (dropwise synthesis method) onto the piece of SSWM-ZnO when it is immersed in water, iron oxide clearly forms on the SSWM surface. This result corroborates the previous view expressed above that it is local acidity in the vicinity of the polar surfaces that controls the $\mathrm{ZnO}$ dissolution rate. When the acidic cation is supplied dropwise the local acidity and the $\mathrm{ZnO}$ dissolution rate are lower and therefore the deposition of iron oxide on the polar $\mathrm{ZnO}$ surface is not impeded.

On the other hand, for values of $\mathrm{pKa}$ in the range of aprox. -9.5 to -5 (mildly acidic cations such as $\mathrm{Cu}^{2+}$ and $\mathrm{Ce}^{3+}$ ) the basic synthesis method allows total substitution to take place and metal oxides with a purity of over $95 \%$ and high yields are obtained.

Since the preparations were carried out at RT and ambient pressure, the main substitution parameters used for the polar SSWM-ZnO template were (i) the aqueous metal ion to zinc molar ratio $\left(\mathrm{R}_{\mathrm{M} / \mathrm{Zn}}\right)$ and (ii) the substitution time $\left(\mathrm{t}_{\mathrm{s}}\right)$. To maximize the purity of the metal oxides obtained (degree of metal substitution; $\mathrm{M} /(\mathrm{M}+\mathrm{Zn})$ molar ratio in the metal oxides) during the synthesis, first the $\mathrm{R}_{\mathrm{M} / \mathrm{Zn}}$ parameter was varied, while the substitution time was kept fixed (Figure 3a) and then the optimal values of $R_{M / Z n}$ (larger dots in Figure 3a) were selected and the substitution time was changed (Figure 3b). 
From Figures $3 \mathrm{a}$ and $3 \mathrm{~b}$ it is clear that all of the metal oxides can be prepared with a purity of over $95 \mathrm{~mol} \%$ provided the appropriate synthesis parameters are selected. It is also to be noted that with the STAH method it is possible to obtain high surface area mixtures of $\mathrm{ZnO}$ with the different metal oxides. The surface area of the prepared materials depends on the degree of metal substitution. Except in the case of SSWM$\mathrm{ZnO}$ substituted with $\mathrm{Cu}$ (ex-nitrate) the specific surface area increases with the degree of substitution (Figure 3c).

For the highest values of purity, the metal oxides show elevated values of specific surface area that range from $18 \mathrm{~m}^{2} \mathrm{~g}^{-1}(\mathrm{CuO}$ (ex-nitrate) $)$ to $275 \mathrm{~m}^{2} \mathrm{~g}^{-1}\left(\mathrm{TiO}_{2}\right)$. As can be observed in Figure 3c, the specific surface area of the iron oxide obtained in this work is more than eight times higher than the highest specific surface area reported in literature for materials prepared by the STAH method [14]. The values of specific surface area obtained are, in general, higher in the case of the synthesized metal oxides than in the case of the original $\mathrm{ZnO}$. This may be due to the restricted growth of the metal hydroxide nuclei inside the electrostatic field of the polar $\mathrm{ZnO}$ surface. Table 2 summarizes the main physical properties of the synthesized metal oxides.

When we used iron (II) sulphate with the basic synthesis method we succeeded in obtaining $\alpha-\mathrm{Fe}_{2} \mathrm{O}_{3}$ but not with a very high value of purity or surface area (64 mol\% purity, $\mathrm{S}_{\mathrm{BET}}=42 \mathrm{~m}^{2} \mathrm{~g}^{-1}, \mathrm{t}_{\mathrm{s}}=2$ days, $\mathrm{R}_{\mathrm{M} / \mathrm{Zn}}=1.1$ ) as occurred in the case of Qin et al. [14]. $\mathrm{Fe}^{2+}$ is slowly oxidized to $\mathrm{Fe}^{3+}$ in an aqueous solution and this may have affected the $\mathrm{Fe}_{2} \mathrm{O}_{3}$ deposition rate during the synthesis. We therefore applied the dropwise synthesis method with this cation and found that the specific surface area of the iron oxide obtained increased dramatically to a value of $166 \mathrm{~m}^{2} \mathrm{~g}^{-1}$ with a purity of over 95 mol\%, probably as a result of a faster oxidation of the highly diluted $\mathrm{Fe}^{2+}$ within the flask containing the SSWM-supported ZnO piece. The use of the SSWM-ZnO template 
with 20.5 wt. $\% \mathrm{ZnO}$ yielded almost pure metal oxides in amounts that ranged from $\sim 12$ wt.\% $\left(\mathrm{TiO}_{2}\right)$ to $\sim 27$ wt.\% $\left(\mathrm{CeO}_{2}\right)$. Figure 2 shows photographs of the different SSWM-supported metal oxides obtained while Figure 4 shows the XRD patterns of the metal oxides. The dashed lines mark the positions of the peaks ascribed to the SSWM support.

The patterns for zinc, copper, cerium and titanium oxides correspond to the crystal structures of zincite $(\mathrm{ZnO})$, tenorite $(\mathrm{CuO})$, cerianite $\left(\mathrm{CeO}_{2}\right)$ and anatase $\left(\mathrm{TiO}_{2}\right)$, respectively. The crystal sizes of the metal oxides obtained by applying the Scherrer equation to the XRD spectra, are fairly small (5-8 nm). The iron oxides show patterns of ill-crystallized materials which are difficult to ascribe to any known crystal structure, whereas the peaks of the spectrum corresponding to titanium dioxide are too wide to discard the possible presence of rutile. To facilitate identification in these cases we used Raman analysis and obtained the spectra shown in Figure 5. As can be seen, the spectra are coincident with those of hematite $\alpha-\mathrm{Fe}_{2} \mathrm{O}_{3}$ [24] and pure anatase $\mathrm{TiO}_{2}$ [25].

The morphologies of the metal oxides are presented in Figure 6. As can be seen, the macroscopic morphology of the $\mathrm{ZnO}$ template (Figure 2) was more or less unchanged after the substitution process. The metal oxides are arranged in arrays of thin nanosheets that have a homogenous length distribution in the 5-7 $\mu \mathrm{m}$ range.

The high resolution TEM images shown in Figure 6 evidence that the nanosheets are formed by nanograins with sizes in the 3-6 nm range (Table 2). This result is in good agreement with the crystal sizes evaluated by XRD or BET analyses, the latter based on the assumption of spherical nanoparticles (Table 2). The three-dimensionally interconnected nanograins give rise to the high porosity of the macroscopic nanosheets. In the electron diffraction patterns of the SSWM-supported metal oxides (Figure 6) all 
the dominant diffraction rings can be indexed to the planes of the same phases analysed by XRD (Figure 4) and Raman spectroscopy (Figure 5).

To test the degree of adhesion between the metal oxide particles and the SSWM, rectangular pieces were introduced into plastic flasks which were then mechanically shaken for several hours at $1200 \mathrm{rpm}$ in order to cause the SSWM pieces to impact continuously and at high speed against the internal walls of the flasks. After 15 hours of testing the SSWM pieces still retained their initial weight.

\subsection{Fenton-like degradation of Methylene Blue}

To test the potential of the present invention we chose the heterogeneous Fenton-like degradation of Methylene Blue (MB). This is an advanced oxidation process that employs iron-based catalysts to promote a reaction between ferrous ions and hydrogen peroxide for producing reactive radicals. It is a proven and effective technology for the destruction of a large number of hazardous and organic pollutants [8, 9]. The use of $\alpha-\mathrm{Fe}_{2} \mathrm{O}_{3}$ catalysts in powder form involves a series of technical challenges, the most important of which is the separation of the nanosized particles from the reaction medium. To overcome this problem, in this work the SSWM-supported $\alpha-\mathrm{Fe}_{2} \mathrm{O}_{3}$ material was employed directly as a structured catalyst for the Fenton-like degradation of methylene blue in aqueous solutions.

First, the activity of the high surface area iron oxide was evaluated. To do this $\alpha-\mathrm{Fe}_{2} \mathrm{O}_{3}$

particles $\left(\mathrm{ex}-\mathrm{Fe}^{3+}\right)$ scratched from the surface of the wire mesh were tested in a batch experiment, as described in the Experimental section.

Figure 7 shows the variation of relative $\mathrm{MB}$ concentration $\left(\mathrm{C} / \mathrm{C}_{0}\right)$ versus reaction time. The data obtained under the same reaction conditions by Cui et al. [10] for a yolk-shell structured $\alpha-\mathrm{Fe}_{2} \mathrm{O}_{3} @$ mesoporous $\mathrm{SiO}_{2}$ catalyst are also plotted for purposes of 
comparison. These authors described the activity of their catalyst as "outstanding" [10]. As can be observed in Figure 7, the structured $\mathrm{Fe}_{2} \mathrm{O}_{3} @$ mesoporous $\mathrm{SiO}_{2}$ nanoreactor shows a high degree of $\mathrm{MB}$ adsorption in the absence of $\mathrm{H}_{2} \mathrm{O}_{2}$ (time $<0$ ), due to the mesoporous $\mathrm{SiO}_{2}$ layer, whereas the high surface area $\mathrm{Fe}_{2} \mathrm{O}_{3}$ prepared in this work does not show any trace of MB adsorption, probably due to chemical incompatibility since there is no other reason why the pore system of the particles (Table 2) should not be readily accessible to the $\mathrm{MB}$ molecules. When $\mathrm{H}_{2} \mathrm{O}_{2}$ was poured into the reaction vessel (time $=0$ ), reactive radicals were immediately formed on the surface of the iron oxide particles by the action of the hydrogen peroxide and reacted in solution with the MB molecules, causing their degradation. The better performance of the iron oxide particles prepared in this work with respect to the highly active structured $\mathrm{Fe}_{2} \mathrm{O}_{3} @$ mesoporous $\mathrm{SiO}_{2}$ nanoreactor [10] (Figure 7) must be ascribed to their much larger active surface areas, causing an increased number of electron transfers between $\mathrm{H}_{2} \mathrm{O}_{2}$ molecules and ferric ions and, therefore, a larger production of reactive radicals.

Stainless steel wire-mesh (SSWM)-supported metal oxide catalysts have been revealed in the recent years by our group as a very promising structured catalytic system $[6,7$, 22, 26-28]. Following this path, a continuous Fenton-like reaction system for the degradation of MB was designed in this work in order to use the SSWM-supported $\alpha-\mathrm{Fe}_{2} \mathrm{O}_{3}$ catalyst, as described in the Experimental section. An image of the reactor is shown in Figure 8. We investigated the $\mathrm{MB}$ conversion as a function of the residence time. As can be observed in the graph of Figure 8, over $80 \%$ conversion was obtained at the highest residence time tested in this work. The catalyst showed good stability during a single experiment and over several reaction cycles. The conversion values obtained in five consecutive cycles were comprised within the standard deviation limits plotted in Figure 8. Leaching of iron is expected to be minimal considering the initial $\mathrm{pH}$ of the 
testing solution (5.7) [29]. Its performance justifies further research and the development of continuous mode Fenton-like reaction systems employing supported metal oxides prepared by sacrificial template synthesis.

\section{Conclusions}

In summary, a general method for producing nanosized metal oxides supported on stainless steel wire meshes is presented. The method is based on the Sacrificial Template-Accelerated Hydrolysis of strongly or mildly acidic cations in aqueous solution. The sacrificial template is a high surface area SSWM-supported $\mathrm{ZnO}$ material with a large proportion of polar surfaces. The nanosized metal oxides $\left(\mathrm{CuO}, \mathrm{CeO}_{2}\right.$, $\alpha-\mathrm{Fe}_{2} \mathrm{O}_{3}$ and $\mathrm{TiO}_{2}$ ) are obtained in high yields (12-27 wt.\%), adhere well to the SSWM pieces and exhibit a high specific surface area $\left(84-275 \mathrm{~m}^{2} \mathrm{~g}^{-1}\right)$ which are one order of magnitude higher than those previously reported for metal oxides prepared by the STAH method. Until now this method has only been able to produce pure metal oxide nanotubes of low surface area which are mainly applied in electrochemical applications [13-21]. The breakthrough of the present contribution is that it shows how to apply the STAH method in the fabrication of advanced functional materials of high surface area that can compete in many other fields, such as heterogeneous catalysis, photocatalysis, environmental remediation, micro-reactors, etc, against high surface area materials prepared by more complex techniques. As proof of the potential of this method we designed a structured reactor with a SSWM-supported $\alpha-\mathrm{Fe}_{2} \mathrm{O}_{3}$ catalyst that was successfully used for the continuous Fenton-like degradation of aqueous Methylene Blue.

\section{Acknowledgements}


The financial support for this research work provided by the Spanish MEC (CTQ201124776) is gratefully acknowledged. Tan T. Vu is grateful to the CSIC for the award of a JAE predoc grant.

\section{References}

[1] M. Hua, S. Zhang, B. Pan, W. Zhang, L. Lv, Q. Zhang, Journal of Hazardous Materials 211-212 (2012) 317-331.

[2] M.M. Arafat, B. Dinan, S.A. Akbar, A.S.M.A. Haseeb, Sensors 12 (2012) 72077258.

[3] M.M. Rahman, A.J.S. Ahammad, J.-H. Jin, S.J. Ahn, J.-J. Lee, Sensors 10 (2010) 4855-4886.

[4] W. Deng, X. Ji, Q. Chen, C.E. Banks, RSC Advances 1 (2011) 1171-1178.

[5] Y. Rao, D.M. Antonelli, Journal of Materials Chemistry 19 (2009) 1937-1944.

[6] L. del Río, G. Marbán, Applied Catalysis B: Environmental 126 (2012) 39-46.

[7] T.T. Vu, L. del Río, T. Valdés-Solís, G. Marbán, Applied Catalysis B:

Environmental 140-141 (2013) 189-198.

[8] S. Rahim Pouran, A.A. Abdul Raman, W.M.A. Wan Daud, Journal of Cleaner Production 64 (2014) 24-35.

[9] E.G. Garrido-Ramírez, B.K.G. Theng, M.L. Mora, Applied Clay Science 47 (2010) 182-192.

[10] Z.-M. Cui, Z. Chen, C.-Y. Cao, L. Jiang, W.-G. Song, Chemical Communications 49 (2013) 2332-2334.

[11] F. Schüth, Angewandte Chemie International Edition 42 (2003) 3604-3622.

[12] T. Valdés-Solís, P. Tartaj, G. Marbán, A.B. Fuertes, Nanotechnology 18 (2007) 145603-145609.

[13] J. Liu, Y. Li, H. Fan, Z. Zhu, J. Jiang, R. Ding, Y. Hu, X. Huang, Chemistry of Materials 22 (2010) 212-217.

[14] L. Qin, Q. Zhu, G. Li, F. Liu, Q. Pan, Journal of Materials Chemistry 22 (2012) 7544-7550.

[15] W. Zeng, F. Zheng, R. Li, Y. Zhan, Y. Li, J. Liu, Nanoscale 4 (2012) 2760-2765.

[16] Y.W. Lee, M.A. Lim, S.W. Kang, I. Park, S.W. Han, Chemical Communications 47 (2011) 6299-6301. 
[17] M.A. Lim, D.H. Kim, C.-O. Park, Y.W. Lee, S.W. Han, Z. Li, R.S. Williams, I. Park, ACS Nano 6 (2011) 598-608.

[18] M.-S. Wu, H.-W. Chang, The Journal of Physical Chemistry C 117 (2013) 25902599.

[19] J. Liu, J. Jiang, M. Bosman, H.J. Fan, Journal of Materials Chemistry 22 (2012) 2419-2426.

[20] Y.-j. Feng, L.-1. Liu, X.-d. Wang, Journal of Materials Chemistry 21 (2011) $15442-15448$.

[21] B.-S. Choi, Y.W. Lee, S.W. Kang, J.W. Hong, J. Kim, I. Park, S.W. Han, ACS Nano 6 (2012) 5659-5667.

[22] T.T. Vu, L. del Río, T. Valdés-Solís, G. Marbán, Materials Research Bulletin 47 (2012) 1577-1586.

[23] A. McLaren, T. Valdés-Solís, G. Li, S.C. Tsang, Journal of the American Chemical Society 131 (2009) 12540-12541.

[24] D.L.A. deFaria, S.V. Silva, M.T. deOliveira, Journal of Raman Spectroscopy 28 (1997) 873-878.

[25] D. Morgan, M. Fett, E. Waclawik, Z. Ding, R.L. Frost, Science Access 2 (2004) 518-519.

[26] G. Marbán, I. López, T. Valdés-Solís, A.B. Fuertes, International Journal of Hydrogen Energy 33 (2008) 6687-6695.

[27] G. Marbán, A. López, I. López, T. Valdés-Solís, Applied Catalysis B:

Environmental 99 (2010) 257-264.

[28] T.T. Vu, L. del Río, T. Valdés-Solís, G. Marbán, Journal of Hazardous Materials 246-247 (2013) 126-134.

[29] J. Herney-Ramirez, M.A. Vicente, L.M. Madeira, Applied Catalysis B:

Environmental 98 (2010) 10-26.

[30] C.M. Chang, A.F. Jalbout, M.K. Wang, C. Lin, Journal of Molecular Structure: THEOCHEM 664-665 (2003) 21-26.

[31] J. Torres, C. Kremer, S. Domínguez, Pure and Applied Chemistry 80 (2008) 13031316.

[32] J.J. Yuan, H.D. Li, Q.L. Wang, Q. Yu, X.K. Zhang, H.J. Yu, Y.M. Xie, Materials Letters 81 (2012) 123-126.

[33] S.Y. Gao, H.D. Li, J.J. Yuan, Y.A. Li, X.X. Yang, J.W. Liu, Applied Surface Science 256 (2010) 2781-2785. 
[34] G. Fierro, G. Ferraris, G. Moretti, Applied Catalysis B: Environmental 91 (2009) 499-506. 


\section{Captions to Figures}

Figure 1. (a) SEM images of a SSWM-supported $\mathrm{ZnO}$ sample consisting of typical $\mathrm{ZnO}$ prisms. (b) SEM images of the same sample after it has been immersed in an aqueous solution of iron (III) nitrate. Drawing) STAH mechanism for a highly acidic cation $\left(\mathrm{Fe}^{3+}\right.$ at ambient conditions or mildly acidic cations under hydrothermal conditions on non polar $\mathrm{ZnO}$ prisms.

Figure 2. SEM images and XRD pattern corresponding to the polar SSWM-supported $\mathrm{ZnO}$ template (SSWM-ZnO). Scheme of the STAH method and images of some SSWM supported metal oxides.

Figure 3. Effect of a) $R_{M / Z n}$ and b) substitution time $\left(t_{s}\right)$ on the degree of metal substitution. c) Variation of the specific surface area with the degree of metal substitution for different SSWM-supported metal oxides.

Figure 4. XRD patterns of the different SSWM-supported metal oxides.

Figure 5. Raman patterns of the ill-crystallized SSWM-supported metal oxides.

Figure 6. SEM and TEM images of the SSWM-supported metal oxides.

Figure 7. Results of Fenton-like degradation of $\mathrm{MB}$ in the dark for the $\alpha-\mathrm{Fe}_{2} \mathrm{O}_{3}$ (ex$\left.\mathrm{Fe}^{3+}\right)$ particles scratched from the wire mesh $\left(0.5 \mathrm{~g} \cdot \mathrm{L}^{-1} \alpha-\mathrm{Fe}_{2} \mathrm{O}_{3}, 50 \mathrm{mg} \cdot \mathrm{L}^{-1} \mathrm{MB}, 18 \mathrm{~g} \cdot \mathrm{L}^{-1}\right.$ $\mathrm{H}_{2} \mathrm{O}_{2}$ ). As a comparison, the data obtained under the same conditions by Cui et al. [10] for a highly active yolk-shell structured $\mathrm{Fe}_{2} \mathrm{O}_{3} @$ mesoporous $\mathrm{SiO}_{2}$ nanoreactor are also plotted.

Figure 8. Continuous Fenton-like reaction system using a SSWM-supported $\alpha-\mathrm{Fe}_{2} \mathrm{O}_{3}$ catalyst for the degradation of MB in aqueous solution. The graph shows the variation of the $\mathrm{MB}$ relative concentration in the exiting solution as a function of residence time. 


\section{Tables}

Table 1. Values of $\mathrm{pKa}$ and STAH results at ambient conditions for the ions used as metal oxide precursors.

\begin{tabular}{|c|c|c|c|}
\hline $\begin{array}{l}\text { Metal } \\
\text { Ion }\end{array}$ & $\begin{array}{l}\mathrm{pKa} \\
{[30,31]}\end{array}$ & STAH method & $\begin{array}{l}\text { Material } \\
\text { obtained }\end{array}$ \\
\hline $\mathrm{TiF}_{6}^{2-}$ & - & $\begin{array}{l}\text { SSWM-ZnO in the precursor solution with } \mathrm{H}_{3} \mathrm{BO}_{3} \text { as a fluoride } \\
\text { scavenger }[32,33]\end{array}$ & \multirow{5}{*}{$\begin{array}{l}\text { Single } \\
\text { oxides }\end{array}$} \\
\hline $\mathrm{Fe}^{3+}$ & -2.2 & $\begin{array}{l}\text { Precursor solution added dropwise to SSWM-ZnO (by means } \\
\text { of a syringe pump) }\end{array}$ & \\
\hline $\mathrm{Ce}^{3+}$ & -5.7 & \multirow{2}{*}{ SSWM-ZnO in the precursor solution } & \\
\hline $\mathrm{Cu}^{2+\mathrm{a})}$ & -8.0 & & \\
\hline $\mathrm{Fe}^{2+}$ & -9.5 & $\begin{array}{l}\text { SSWM-ZnO in the precursor solution. Gradual oxidation of } \\
\mathrm{Fe}^{2+} \text { to } \mathrm{Fe}^{3+} \text { (best results obtained with a syringe pump) }\end{array}$ & \\
\hline $\mathrm{Co}^{2+}$ & -9.7 & \multirow{3}{*}{ SSWM-ZnO in the precursor solution } & \multirow{3}{*}{$\begin{array}{l}\text { Mixed } \\
\text { oxides }\end{array}$} \\
\hline $\mathrm{Ni}^{2+}$ & -9.9 & & \\
\hline $\mathrm{Mn}^{2+}$ & -10.6 & & \\
\hline
\end{tabular}

a) Although in most cases the precursor salts were the corresponding nitrates, in the case of copper the specific surface area of the resulting oxide is strongly dependent on the counterion of the precursor salt. Thus, copper nitrate gave rise to a pure oxide with a specific surface area of around $18 \mathrm{~m}^{2} \mathrm{~g}^{-1}$, whereas copper acetate yielded a copper oxide with a specific surface area of $84 \mathrm{~m}^{2} \mathrm{~g}^{-1}$. This was due to the hydrolysis of the acetate that produced a slight increase in the $\mathrm{pH}$ of the solution [34], thereby slowing down the dissolution of $\mathrm{ZnO}$ and causing the $\mathrm{CuO}$ to be more uniformly dispersed on the remaining $\mathrm{ZnO}$ surface; ${ }^{\text {b) }}$ For weakly acidic cations, with $\mathrm{pKa}$ values below around -9.5 , only partial substitutions were obtained, leading to mixed oxides which will be the subject of a future work. 
Table 2. Physical properties of the synthesized metal oxides.

\begin{tabular}{|c|c|c|c|c|c|c|c|c|}
\hline \multirow{2}{*}{ Oxide } & \multirow{2}{*}{$\begin{array}{l}\text { Synthesis } \\
\text { method }\end{array}$} & \multirow{2}{*}{$\begin{array}{c}\text { Yield } \\
\text { [wt.\%] }\end{array}$} & \multirow{2}{*}{$\begin{array}{l}\text { Purity } \\
{[\mathrm{mol} \%]}\end{array}$} & \multirow{2}{*}{$\begin{array}{c}\mathrm{S}_{\mathrm{BET}} \\
{\left[\mathrm{m}^{2} \mathrm{~g}^{-1}\right]}\end{array}$} & \multirow{2}{*}{$\begin{array}{c}\text { Pore size } \\
\text { maxima } \\
{[\mathrm{nm}]}\end{array}$} & \multicolumn{3}{|c|}{$\begin{array}{c}\text { Crystal size } \\
{[\mathrm{nm}]}\end{array}$} \\
\hline & & & & & & XRD & TEM & BET \\
\hline $\begin{array}{l}\mathrm{ZnO} \\
\text { template }\end{array}$ & $\begin{array}{l}\mathrm{Vu} e t \\
a l .[7]\end{array}$ & 20.5 & 100.0 & 80 & 16,109 & 13 & 11 & 13 \\
\hline $\begin{array}{l}\mathrm{CuO} \\
\text { (ex-acetate) }\end{array}$ & $\begin{array}{c}\text { Basic } \\
\mathrm{R}_{\mathrm{M} / \mathrm{Zn}}=1.5 \\
\mathrm{t}_{\mathrm{s}}=1 \text { day }\end{array}$ & 22.2 & 95.3 & 84 & 53 & 8 & 6 & 11 \\
\hline $\mathrm{CeO}_{2}$ & $\begin{array}{c}\text { Basic } \\
\mathrm{R}_{\mathrm{M} / \mathrm{Zn}}=5 \\
\mathrm{t}_{\mathrm{s}}=5 \text { days }\end{array}$ & 26.6 & 95.6 & 122 & 10 & 5 & 5 & 7 \\
\hline $\begin{array}{l}\alpha-\mathrm{Fe}_{2} \mathrm{O}_{3} \\
\left(\mathrm{ex}-\mathrm{Fe}^{2+}\right)\end{array}$ & $\begin{array}{c}\text { Dropwise } \\
\mathrm{R}_{\mathrm{M} / \mathrm{Zn}}=2 \\
\mathrm{t}_{\mathrm{s}}=2 \text { day }\end{array}$ & 18.3 & 95.1 & 166 & 8 & - & - & 7 \\
\hline $\begin{array}{l}\alpha-\mathrm{Fe}_{2} \mathrm{O}_{3} \\
\left(\mathrm{ex}-\mathrm{Fe}^{3+}\right)\end{array}$ & $\begin{array}{l}\text { Dropwise } \\
\mathrm{R}_{\mathrm{M} / \mathrm{Zn}}=1.1 \\
\mathrm{t}_{\mathrm{s}}=2 \text { days }\end{array}$ & 13.5 & 97.6 & 220 & 3,12 & - & 3 & 5 \\
\hline $\begin{array}{l}\mathrm{TiO}_{2} \\
\text { (anatase) }\end{array}$ & $\begin{array}{c}\text { Basic } \\
\mathrm{R}_{\mathrm{M} / \mathrm{Zn}}=1.5 \\
\mathrm{t}_{\mathrm{s}}=1 \text { day }\end{array}$ & 11.6 & 97.8 & 275 & 4 & 5 & $3-6$ & 6 \\
\hline
\end{tabular}




\section{Figures}
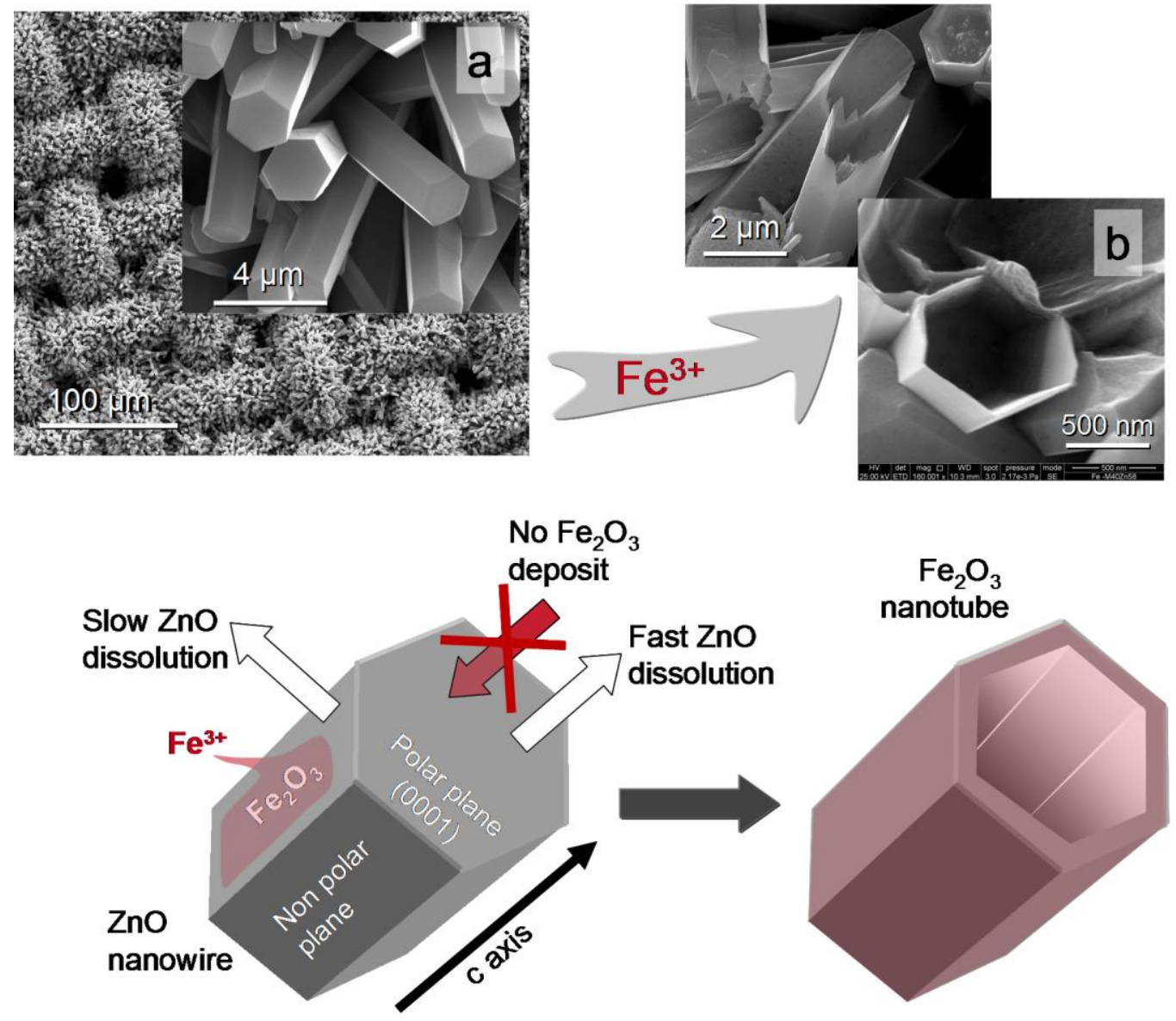

Figure 1 


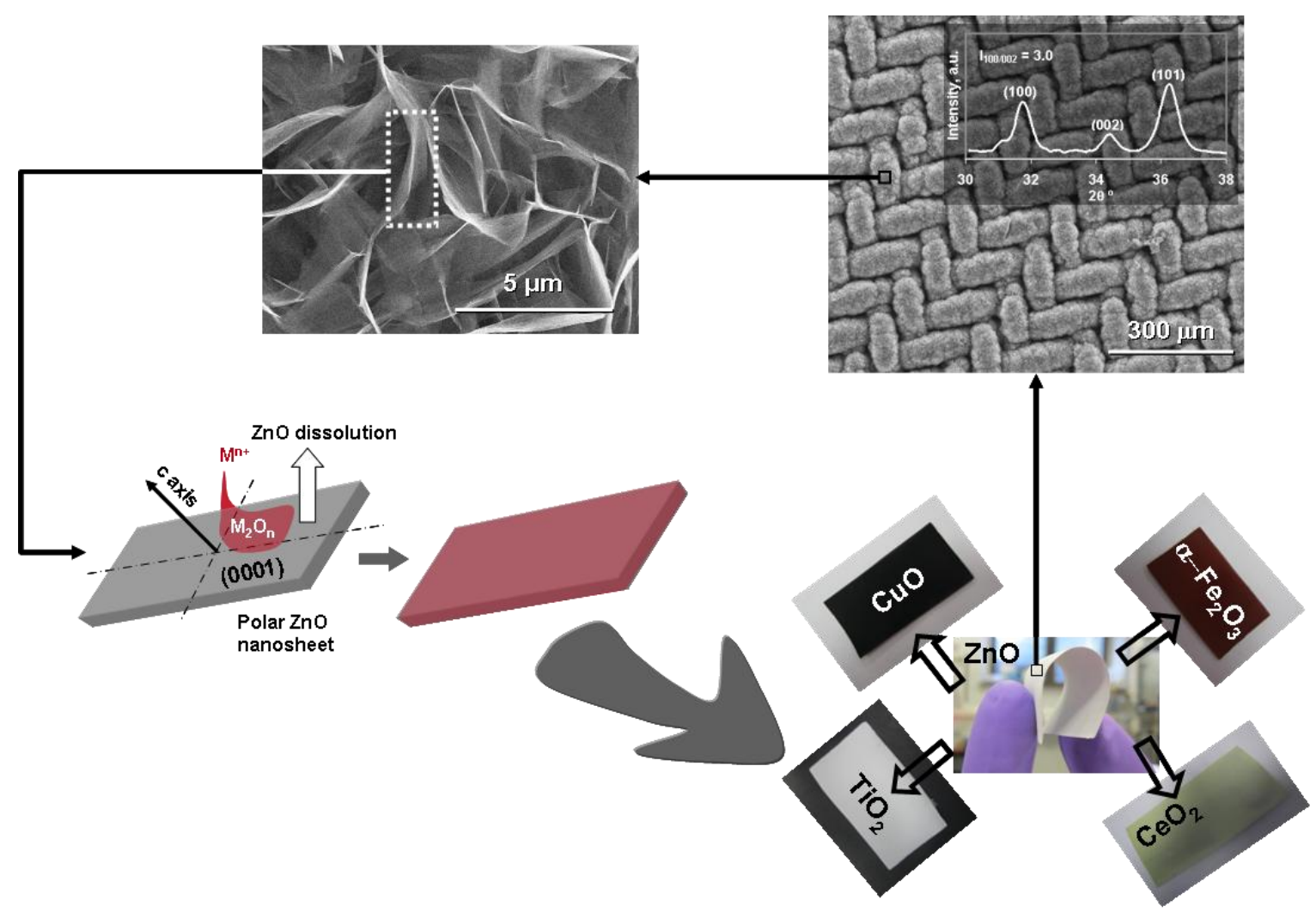

Figure 2 

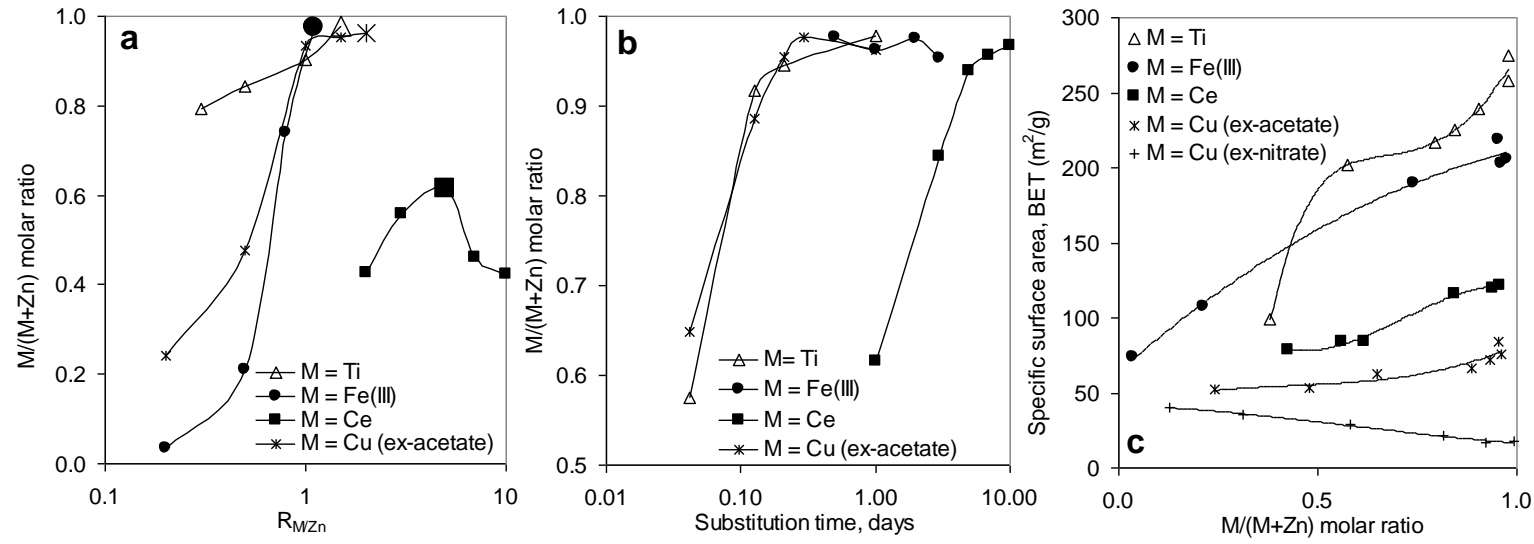

Figure 3 


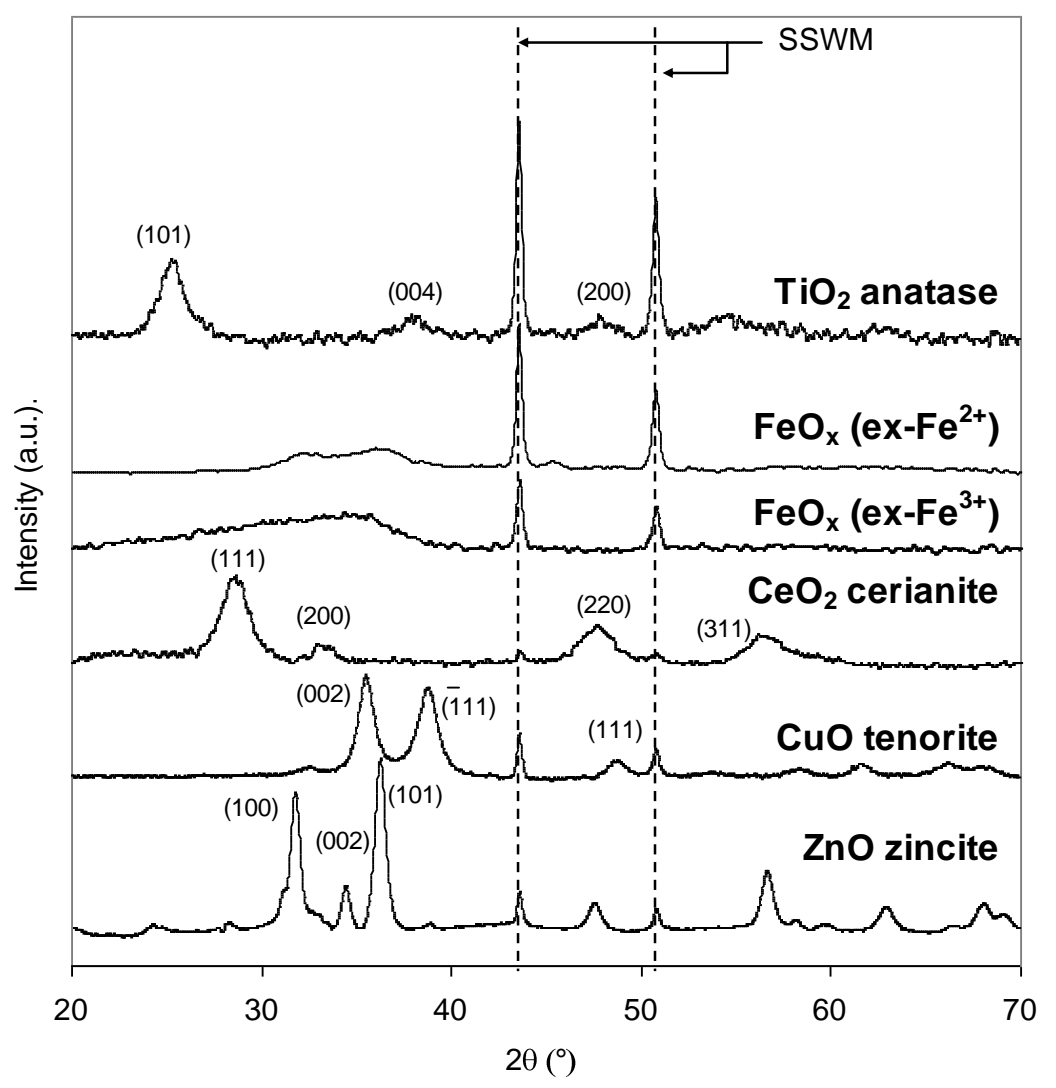

Figure 4 


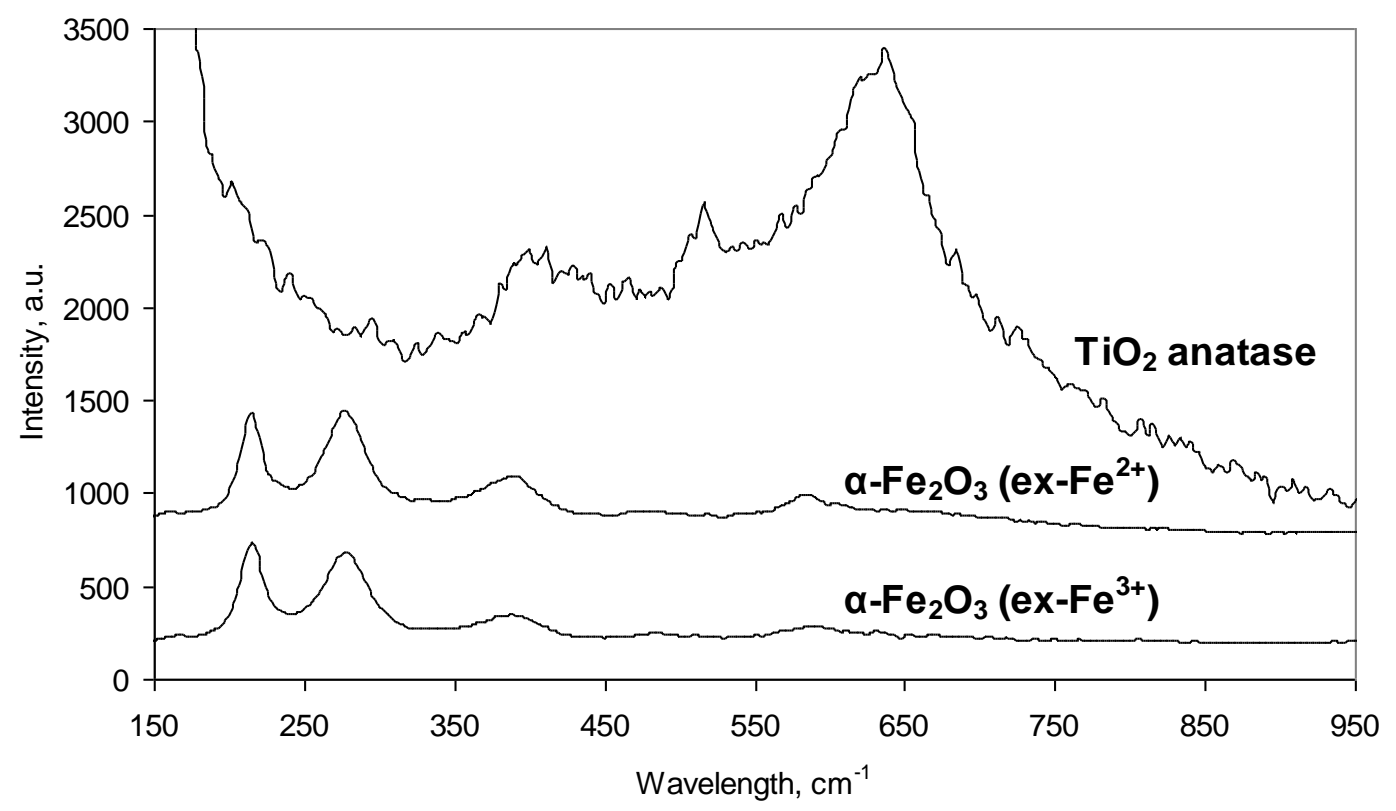

Figure 5 


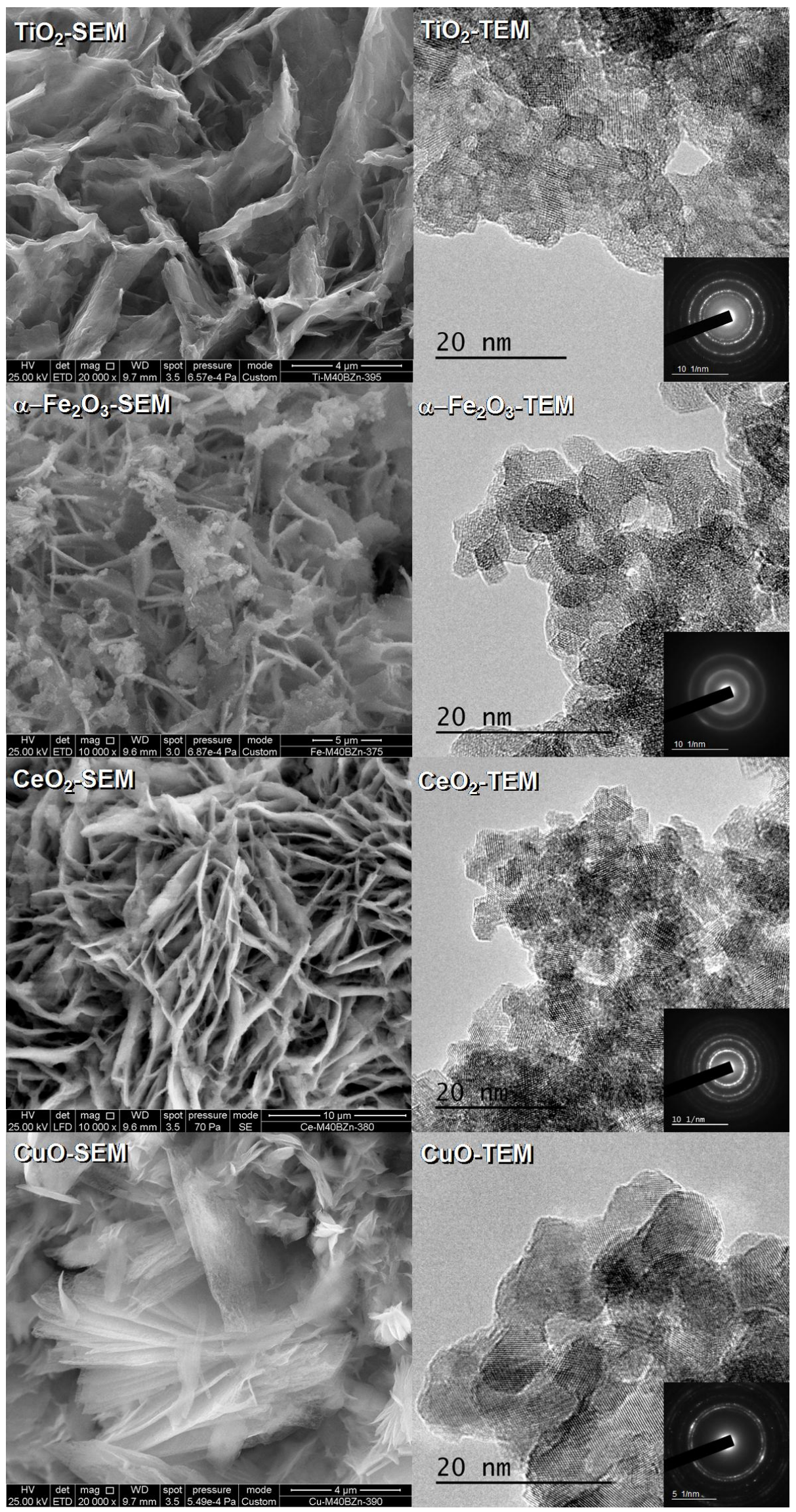

Figure 6 


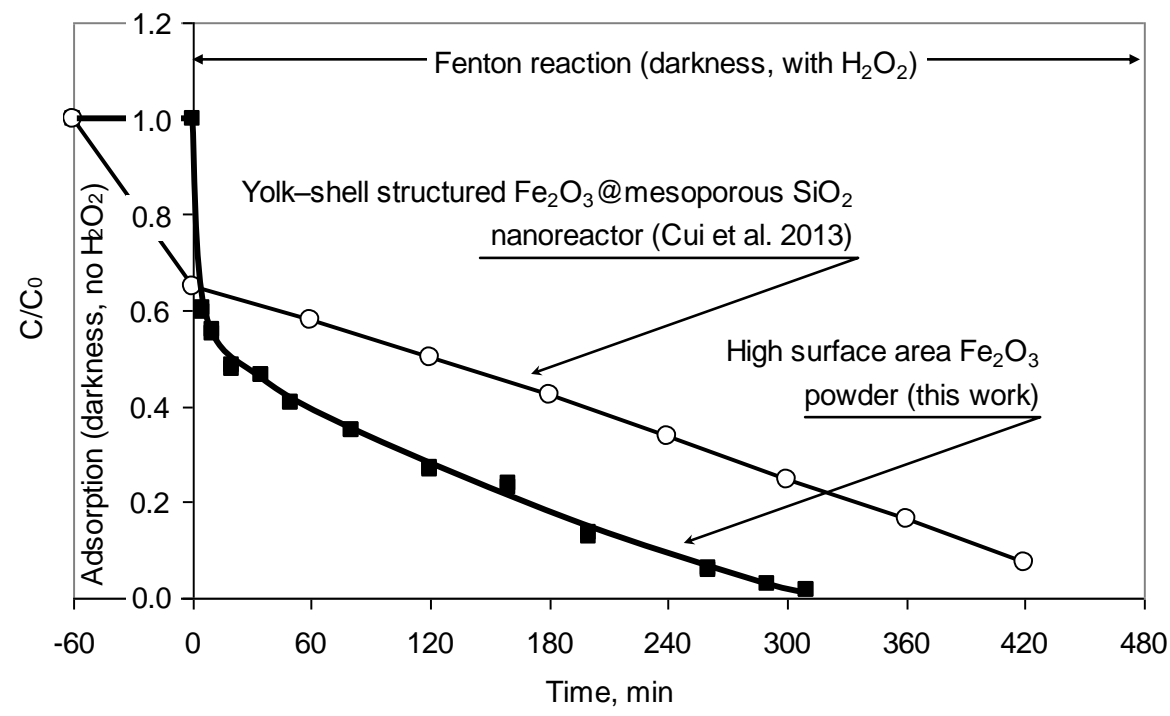

Figure 7 


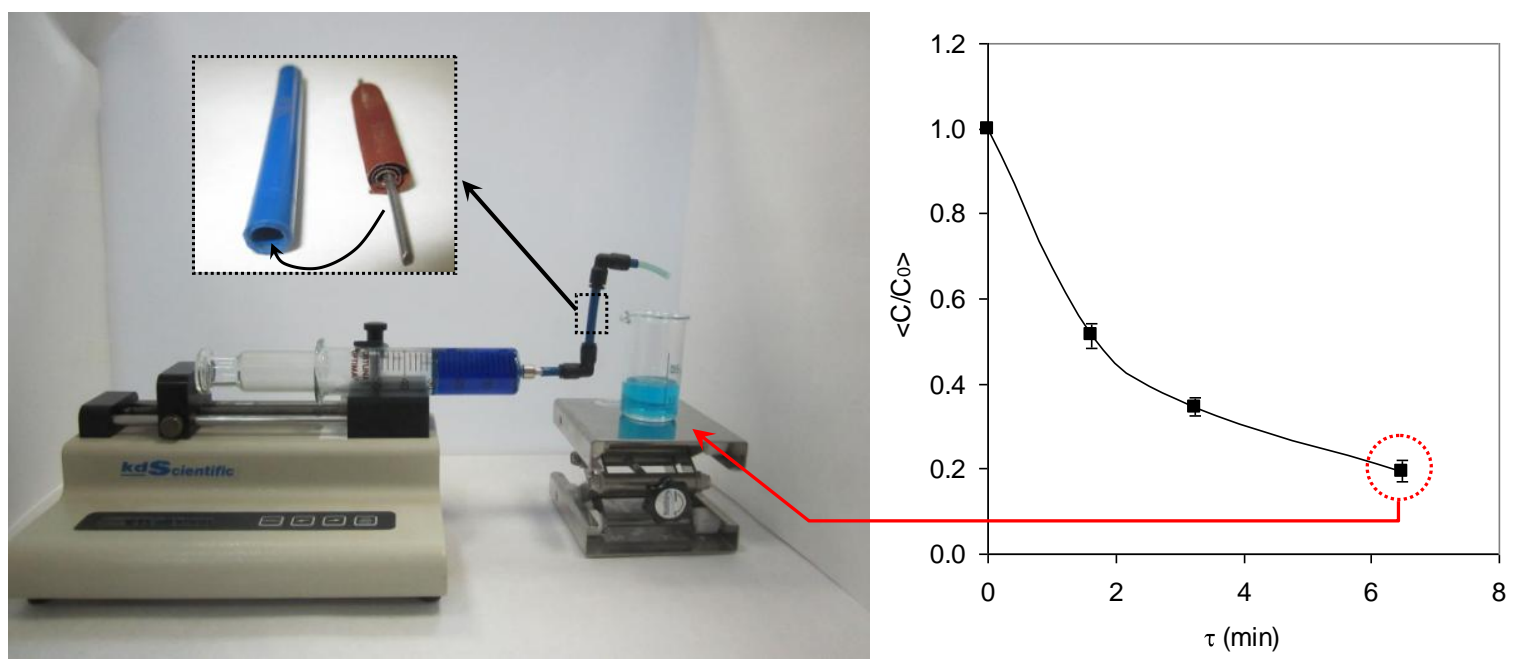

Figure 8 